\title{
Analysis of Chemically Reactive Hydromagnetic Maxwell Fluid Conveying Tiny Particles Due to Navier Partial Slip
}

\author{
Olubode Kolade Koriko, Victor Ayodeji Oladipupo*, \\ Adeola John Omowaye, Sunday Tunbosun Oni \\ Department of Mathematical Sciences, Federal University of Technology, Akure, Nigeria \\ Email: okkoriko@futa.edu.ng, *victorayodejioladipupo@gmail.com, ajomowaye@futa.edu.ng, sundayoni1958@yahoo.ca
}

How to cite this paper: Koriko, O.K., Oladipupo, V.A., Omowaye, A.J. and Oni, S.T. (2021) Analysis of Chemically Reactive Hydromagnetic Maxwell Fluid Conveying Tiny Particles Due to Navier Partial Slip. Open Access Library Journal, 8: e8003. https://doi.org/10.4236/oalib.1108003

Received: September 24, 2021

Accepted: October 25, 2021

Published: October 28, 2021

Copyright $\odot 2021$ by author(s) and Open Access Library Inc.

This work is licensed under the Creative Commons Attribution International License (CC BY 4.0).

http://creativecommons.org/licenses/by/4.0/

\section{(c) (i) Open Access}

\begin{abstract}
The analysis of nanofluids in the solar thermal system is very fascinating owing to its important engineering applications (i.e., solar collectors). Aside from these the non-Newtonian boundary layer fluid flow has experienced considerable attention due to uprising engineering applications in the solar thermal field. This work investigates the analysis of chemically reactive hydromagnetic Maxwell fluid conveying tiny particles due to Navier partial slip. The governing equations that model the transport phenomena were transformed using suitable similarity variables. The boundary value problem of the corresponding coupled nonlinear ordinary differential equations was solved numerically using the shooting technique together with the fourth-order Runge-Kutta integration scheme and in-built bvp4c package of MATLAB. The effects of various controlling parameters on velocity, temperature, and concentration distributions were presented graphically and studied theoretically. Furthermore, the study reveals that the Navier slip parameter $(\delta)$ increases as the velocity distribution decreases, while it enhances both the temperature and concentration distributions, increase in the radiation parameter $(N r)$ enhances the temperature distribution, and the chemical reaction $(\gamma)$ increment leads to decrease in concentration distribution.
\end{abstract}

\section{Subject Areas}

Fluid Mechanics

\section{Keywords}

Hydromagnetic, Upper-Convected Maxwell Fluid, Navier Partial Slip, Chemical Reaction, Nanofluid, Thermal Radiation 


\section{Introduction}

James Clerk Maxwell coined the concept of Maxwell fluid in 1867. The fluid is described as a viscoelastic fluid that consists of elasticity and viscosity which are characterized by solely elastic spring and solely viscous damper in series connection [1]. In the time after, the plethora of research has been executed on Maxwell fluid flow; see Refs. [2]-[11]. Imran et al. [12] experimented with the Maxwell boundary layer fluid flow generalization on an accelerated infinite vertical plane accompanied by Newtonian heating and slip at the wall. Ramesh et al. [13] [14] studied the behavior of Maxwell nanoparticles fluid flow beyond a Riga surface involving chemical reaction and radiation. Omowaye and Animasaun [15] worked on upper convected Maxwell fluid with variability in physical composition past a melting surface with thermal stratification. It was discovered that the thermal stratification affected both the longitudinal and transverse velocities. Also, the thermal stratification retards the velocity as a result of free stream temperature. Koriko et al. [16] analyzed the boundary layer of generalized fluid flow via a melting thermally stratified plate with thermo-physical properties. Shehzad et al. [17] presented the hydromagnetic flow of Maxwell fluid across a bi-directional stretchable sheet involving prescribed surface heat flux and temperature. Salah et al. [18] worked on the Rapid flow of Maxwell fluid in a rotating frame and porous medium.

Fluid conveying tiny particles is simply referred to as nanofluid. Fluid conveying tiny particles are blends of a handful of tiny particles like metal oxide particles $\left(\mathrm{Al}_{2} \mathrm{O}_{3}, \mathrm{TiO}, \mathrm{CuO}\right.$, etc.) with a base fluid-like ethylene-glycol or $\mathrm{H}_{2} \mathrm{O}$, with the dimension ranging from $1-100 \mathrm{~nm}$, possessing high thermal conductivities. This phenomenon was christened by Choi and Eastman [19]. Series of research has been conducted on the latter recently; see Rashidi et al. [20] studied the effects of buoyancy and thermal radiation on hydromagnetic flow of fluid conveying tiny particles past a stretching mechanism. It was observed that the reduction and escalation of the temperature and the velocity of the fluid conveying tiny particles respectively are down to the uprise of the buoyancy parameter. Rout and Mishra [21] presented a comparative study on hydromagnetic fluid conveying tiny particles via a stretching surface with thermal energy transport. It was reported that the fluid flow was conveying tiny particles retards owing to the proliferation of heat generation parameter but the rate of mass transport experienced enhancement due to chemical reaction being healthy qualitatively. Ho [22] examined the quantum particles in a state of fluid via the Dirac equation. Shoaib et al. [23] carried out a numerical investigation on hydrodynamic hybrid fluid conveying tiny particles swirling flow beyond a stretching surface in the presence of thermal radiation. It was reported that greater values of magnetic parameter lead to higher frictional forces which boils down to deterioration and proliferation in velocity and temperature fields, respectively. Zainal and Pop [24] deliberated on hydromagnetic fluid conveying tiny particles beyond a permeable moving force with radiation. Animasaun et al. [25] ex- 
plored Eyring-Powell non-Newtonian fluid conveying tiny gold particles caused by buoyancy and surface slip velocity.

Navier partial slip for viscous fluids is more or less an assumption, which depicts the experiences of velocity at the solid wall to be zero relative to that boundary [26]. Suneetha et al. [27] presented the Soret effect on time-dependent fluid conveying tiny particles involving radiation and Navier slip condition. It was reported that the Soret number increment around the boundary layer was due to an escalation in concentration. More so, velocity slip increment leads to retardation in the velocity field while the temperature field experienced the reversal effect of velocity slip. The moving contact line issue of characterized limits for the no-slip condition was discussed by Ren et al. [28]. Fernandes et al. [29] implemented the partial slip condition for open-source computational archive finite-volume-based. Venkatesan and Ganesan [30] computed droplets impinged substances via Navier partial slip condition. Navier partial slip condition involving a squeeze flow problem was examined by Fang et al. [31]. Bolanos and Vernescu [32] discussed the Navier partial slip and slip length derivation for viscous flows past a rough boundary.

The analysis of chemically reactive hydromagnetic Maxwell fluid conveying tiny particles via Navier partial slip has been ignored in several works of literature reviewed. This has brought about the motivation to carry out this research.

Therefore, this study shall be devoted to the undermentioned research questions:

- What is the significance of thermal radiation on chemically reactive hydromagnetic Maxwell fluid conveying tiny particles?

- How influential are thermophoresis and Brownian motion to chemically reactive hydromagnetic Maxwell fluid conveying tiny particles?

- What is Navier partial slip effect on chemically reactive hydromagnetic Maxwell fluid conveying tiny particles?

- Is there any variable suitable to boost the local skin friction coefficient during the flow of this fluid?

\section{Research Methodology}

Consider steady 2-D flow of an incompressible Maxwell fluid conveying tiny particles due to Navier partial slip. As illustrated in Figure 1, the sheet is synchronizing with the coordinate $y=0$, with the flow being interned to $y>0$. The flow is catalyzed by the stretching of the sheet, caused by the simultaneity of two equal and opposite forces on $\mathrm{x}$-coordinate. Retaining the origin at $(0,0)$, the sheet experienced stretch input with variation of speed directly proportional to the distance from the slit. Uniform magnetic field strength $B_{0}$ is utilized in $y$-coordinate. The magnetic Reynolds number is pint-size and so the induced magnetic field is negligible. The plate temperature $T_{w}$ and plate concentration $C_{w}$ are uniform at the surface and these values are assumed to be greater than the free stream temperature and concentration, $T_{\infty}$ and $C_{\infty}$, respectively. Both 


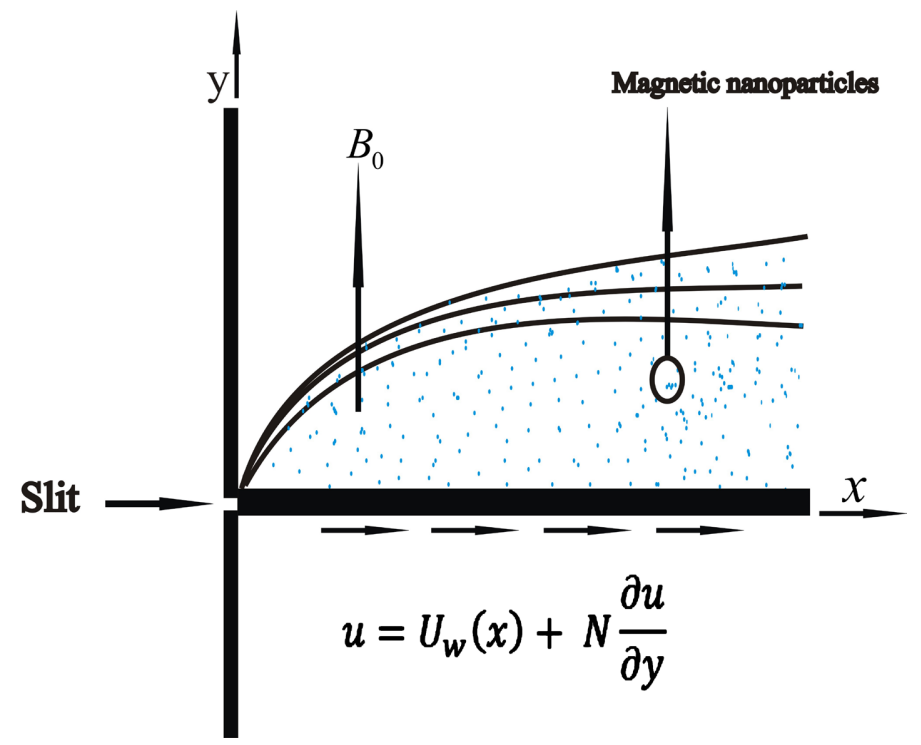

Figure 1. Physical configuration and coordinate system.

the fluid and nanoparticles are in the thermal equilibrium state. Nanofluid thermo-physical properties are constant though assumed. Based on Buongiorno [33] and boundary layer approximation, the governing equation was formulated from Ramesh et al. [13] and modified into:

$$
\begin{gathered}
\frac{\partial u}{\partial x}+\frac{\partial v}{\partial y}=0 \\
u \frac{\partial u}{\partial x}+v \frac{\partial u}{\partial y}+k_{0}\left(u^{2} \frac{\partial^{2} u}{\partial x^{2}}+v^{2} \frac{\partial^{2} u}{\partial y^{2}}+2 u v \frac{\partial^{2} u}{\partial x \partial y}\right)=v \frac{\partial^{2} u}{\partial y^{2}}-\frac{\sigma B_{0}^{2}}{\rho_{f}}\left(u+k_{0} v \frac{\partial u}{\partial y}\right) \\
u \frac{\partial T}{\partial x}+v \frac{\partial T}{\partial y}=\alpha \frac{\partial^{2} T}{\partial y^{2}}-\frac{1}{\rho_{f} C_{p}} \frac{\partial q_{r}}{\partial y}+\tau\left[\frac{D_{B}}{\Delta C}\left(\frac{\partial C}{\partial y} \frac{\partial T}{\partial y}\right)+\left(\frac{D_{T}}{T_{\infty}}\right)\left(\frac{\partial T}{\partial y}\right)^{2}\right] \\
u \frac{\partial C}{\partial x}+v \frac{\partial C}{\partial y}=D_{B} \frac{\partial^{2} C}{\partial y^{2}}+\left(\frac{D_{T} \Delta C}{T_{\infty}}\right)\left(\frac{\partial^{2} T}{\partial y^{2}}\right)-R\left(C-C_{\infty}\right)
\end{gathered}
$$

The boundary conditions are:

$$
\begin{gathered}
u=U_{w}(x)+N \frac{\partial u}{\partial y}, \quad v=0, T=T_{w}, C=C_{w} \text { at } y=0, \\
u \rightarrow 0, \quad v \rightarrow 0, \quad T \rightarrow T_{\infty}, \quad C \rightarrow C_{\infty} \text { as } y \rightarrow \infty .
\end{gathered}
$$

where $U_{w}(x)=c x$ is the stretching velocity and $c>0$ this is known as stretching rate.

By Rosseland approximation, the radiative heat flux is given by:

$$
q_{r}=-\frac{4 \sigma^{*}}{3 k^{*}} \frac{\partial T^{4}}{\partial y}
$$

It is assumed that the variations in temperature within the flow are pint-size for $T^{4}$ to be expressed linearly after the implementation of Taylor series in other to expand $T^{4}$ about the temperature away from the wall $T_{\infty}$ and ignor- 
ing the higher order terms, leads to:

$$
T^{4} \cong 4 T_{\infty}^{3} T-3 T_{\infty}^{4}
$$

In order to avoid truncation of higher order terms used in Equation (8), the radiative heat flux in Equation (7) was modified by adopting implicit differentiation and gives:

$$
q_{r}=-\frac{4 \sigma^{*}}{3 k^{*}} 4 T^{3} \frac{\partial T}{\partial y}
$$

Substituting (9) into (3) leads to

$$
\begin{aligned}
u \frac{\partial T}{\partial x}+v \frac{\partial T}{\partial y}= & \alpha \frac{\partial^{2} T}{\partial y^{2}}+\frac{1}{\rho_{f} c_{p}} \frac{\partial}{\partial y}\left(\frac{4 \sigma^{*}}{3 k^{*}} 4 T^{3} \frac{\partial T}{\partial y}\right) \\
& +\tau\left[\frac{D_{B}}{\Delta C}\left(\frac{\partial C}{\partial y} \frac{\partial T}{\partial y}\right)+\left(\frac{D_{T}}{T_{\infty}}\right)\left(\frac{\partial T}{\partial y}\right)^{2}\right] .
\end{aligned}
$$

Similarity transformations are:

$$
\eta=\left(\frac{U_{w}}{v X}\right)^{\frac{1}{2}} y, f(\eta)=\frac{\psi}{\left(v \times U_{w}\right)^{\frac{1}{2}}}, \theta(\eta)=\frac{T-T_{\infty}}{T_{w}-T_{\infty}}, \phi(\eta)=\frac{C-C_{\infty}}{C_{w}-C_{\infty}}
$$

The fundamental equations of the boundary layer (2), (4) and (10) are transformed as:

$$
\begin{gathered}
\frac{\mathrm{d}^{3} f}{\mathrm{~d} \eta^{3}}+f \frac{\mathrm{d} f}{\mathrm{~d} \eta} \frac{\mathrm{d} f}{\mathrm{~d} \eta}-\frac{\mathrm{d}^{2} f}{\mathrm{~d} \eta^{2}}-\beta\left(f^{2} \frac{d^{3} f}{d \eta^{3}}-2 f \frac{\mathrm{d} f}{\mathrm{~d} \eta} \frac{\mathrm{d}^{2} f}{\mathrm{~d} \eta^{2}}\right)-M\left(\frac{\mathrm{d} f}{\mathrm{~d} \eta}-\beta f \frac{\mathrm{d} f}{\mathrm{~d} \eta^{2}}\right)=0, \\
\left(1+\frac{1}{N r}+\frac{1}{N r} A^{3} \theta^{3}+3 \frac{1}{N r} A^{2} \theta^{2}+3 \frac{1}{N r} A \theta\right) \frac{\mathrm{d}^{2} \theta}{\mathrm{d} \eta^{2}}+P r\left(f \frac{\mathrm{d} \theta}{\mathrm{d} \eta}+N b \frac{\mathrm{d} \theta}{\mathrm{d} \eta} \frac{\mathrm{d} \phi}{\mathrm{d} \eta}\right. \\
\left.+N t\left(\frac{\mathrm{d} \theta}{\mathrm{d} \eta}\right)^{2}\right)+\frac{1}{N r}\left(A^{3}\left(\frac{\mathrm{d} \theta}{\mathrm{d} \eta}\right)^{4}+3 A^{2}\left(\frac{\mathrm{d} \theta}{\mathrm{d} \eta}\right)^{3}+3 A\left(\frac{\mathrm{d} \theta}{\mathrm{d} \eta}\right)^{2}\right)=0, \\
\frac{\mathrm{d}^{2} \phi}{\mathrm{d} \eta^{2}}+L e P r\left(f \frac{\mathrm{d} \phi}{\mathrm{d} \eta}-\gamma \phi\right)+\frac{N t}{N b} \frac{\mathrm{d}^{2} \theta}{\mathrm{d} \eta^{2}}=0 .
\end{gathered}
$$

The boundary conditions are:

$$
\begin{gathered}
f=0, \frac{\mathrm{d} f}{\mathrm{~d} \eta}=1+\delta \frac{\mathrm{d}^{2} f}{\mathrm{~d} \eta^{2}}, \theta=1, \phi=1 \quad \text { at } \eta=0, \\
f \rightarrow 0, \frac{\mathrm{d} f}{\mathrm{~d} \eta} \rightarrow 0, \theta \rightarrow 0, \phi \rightarrow 0 \quad \text { as } \eta \rightarrow \infty .
\end{gathered}
$$

$M=\frac{\sigma B_{0}^{2}}{\rho_{f} c}$ Hartmann number, $\beta=k_{0} c$ Deborah number, $N r=\frac{3 k^{*} k}{16 \sigma^{*} T_{\infty}^{3}}$ Radiation parameter, $N t=\frac{\tau D_{T}\left(\theta_{w}-1\right)}{v}$ Thermophoresis parameter, $N b=\frac{\tau D_{B} C_{\infty}\left(\phi_{w}-1\right)}{v}$ Brownian motion parameter, $A=\theta_{w}-1$ Constant, Le $=\frac{\alpha}{D_{B}}$ Lewis number, $\gamma=\frac{R}{c}$ Chemical reaction parameter, $\delta$ Navier 
partial slip parameter and $\operatorname{Pr}=\frac{v}{\alpha}$ Prandtl number.

\section{Engineering Physical Quantities of Interest}

The physical quantities of interest in the present study are non-dimensional local skin friction coefficient $C_{f x}$, local Nusselt number $N u_{x}$, and local Sherwood number $S h_{x}$ given by:

$$
\begin{aligned}
& C_{f x}=\frac{\tau_{w}}{\rho U_{w}^{2}(x)}, \tau_{w}=\left.\mu \frac{\partial u}{\partial y}\right|_{y=0}, N u_{x}=\frac{q_{w} x}{K\left(T_{w}-T_{\infty}\right)} \\
& q_{w}=-\left.K \frac{\partial T}{\partial y}\right|_{y=0}, S h_{x}=\frac{q_{m} x}{D_{B}\left(C_{w}-C_{\infty}\right)}, q_{m}=-\left.D_{B} \frac{\partial C}{\partial y}\right|_{y=0}, R e_{x}=\frac{U_{w}(x) x}{v}
\end{aligned}
$$

where $\tau_{w}, q_{w}, q_{m}$, and $R e_{x}$ are the skin friction at the wall, heat flux at the wall, mass flux at the wall, and local Reynolds number.

Expressing Equation (17) in dimensionless form leads to:

$$
C_{f x} R e_{x}^{\frac{1}{2}}=f^{\prime \prime}(\eta), N u_{x} R e_{x}^{-\frac{1}{2}}=-\theta^{\prime}(\eta), S h_{x} R e_{x}^{-\frac{1}{2}}=-\phi^{\prime}(\eta)
$$

\section{Numerical Solution}

\section{Implementation of Shooting Technique}

First step: Reduction of Equations (12)-(14) alongside the boundary conditions (15) and (16) into the system of first-order ordinary differential equations

$$
\begin{aligned}
& f=y_{1}, \frac{\mathrm{d} f}{\mathrm{~d} \eta}=y_{2}, \frac{\mathrm{d}^{2} f}{\mathrm{~d} \eta}=y_{3}, \theta=y_{4}, \frac{\mathrm{d} \theta}{\mathrm{d} \eta}=y_{5}, \phi=y_{6}, \frac{\mathrm{d} \phi}{\mathrm{d} \eta}=y_{7} \\
& \frac{\mathrm{d} y_{1}}{\mathrm{~d} \eta}=y_{2}, \frac{\mathrm{d} y_{2}}{\mathrm{~d} \eta}=y_{3}, \\
& \frac{\mathrm{d} y_{3}}{\mathrm{~d} \eta}=\frac{-y_{1} y_{3}+y_{3}^{2}-2 \beta y_{1} y_{2} y_{3}+M y_{2}-M \beta y_{1} y_{3}}{1-\beta y_{1}^{2}}, \frac{\mathrm{d} y_{4}}{\mathrm{~d} \eta}=y_{5}, \\
& \frac{\mathrm{d} y_{5}}{\mathrm{~d} \eta}=\frac{-P r y_{1} y_{5}-P r N b y_{5} y_{7}-P r N t y_{5}^{2}-\frac{1}{N r} A^{3} y_{5}^{4}-3 \frac{1}{N r} A^{2} y_{5}^{3}-3 \frac{1}{N r} A y_{5}^{2}}{1+\frac{1}{N r}+\frac{1}{N r} A^{3} y_{4}^{3}+3 \frac{1}{N r} A^{2} y_{4}^{2}+3 \frac{1}{N r} A y_{4}} \\
& \frac{\mathrm{d} y_{6}}{\mathrm{~d} \eta}=y_{7}, \\
& \frac{\mathrm{d} y_{7}}{\mathrm{~d} \eta}=-L e P r y_{1} y_{7}+L e P r \gamma y_{6} \\
& -\operatorname{PrNty}_{1} y_{5}-\operatorname{Pr} N b N t y_{5} y_{7}-\operatorname{Pr}_{N} t^{2} y_{5}^{2}-\frac{N t}{N r} A^{3} y_{5}^{4}-3 \frac{N t}{N r} A^{2} y_{5}^{3}-3 \frac{N t}{N r} A y_{5}^{2} \\
& +\frac{N b+\frac{N b}{N r}+\frac{N b}{N r} A^{3} y_{4}^{3}+3 \frac{N b}{N r} A^{2} y_{4}^{2}+3 \frac{N b}{N r} A y_{4}}{S}
\end{aligned}
$$

Subject to :

$$
\begin{aligned}
& y_{1}(0)=0, y_{2}(0)=1+\delta y_{3}, y_{4}(0)=1, y_{5}(0)=1 \quad \text { at } \eta=0, \\
& y_{1} \rightarrow 0, y_{2} \rightarrow 0, y_{4} \rightarrow 0, y_{6} \rightarrow 0 \quad \text { as } \eta \rightarrow \infty .
\end{aligned}
$$

Second step: Involves employing fourth order Runge-Kutta together with 
MATLAB package (bvp4c) to compute (19).

Solving the boundary value problem on an infinite interval basis is unrealizable, and therefore it is non-practical to solve for a considerable finite interval. In this study, the step size and convergence criterion were chosen to be 0.001 and $10^{-4}$, respectively. The far-field boundary conditions were applied for the similarity variables at a finite value denoted here by $\eta_{\max }$, thus

$$
\eta_{\max }=10, f^{\prime}(10)=0, \theta(10)=0, \phi(10)=0
$$

The preference of $\eta_{\max }=10$ ensured that the entire numerical solutions attain the asymptotic estimates accurately.

\section{Results and Discussion}

In given a comprehensive and detailed report of our findings, values have been assigned to the governing parameters as $\beta=0.2, M=0.5, N r=2.0$, $L e=1.0, \operatorname{Pr}=3.0, N t=0.1, N b=0.1, \gamma=0.2, A=0.3, \delta=1.0$. The accuracy of the computed solution is certified by comparing the present result with Ramesh et al. [13] in Table 1.

Table 2 and Table 3 show that both the Deborah number and Magnetic number increases the local skin friction coefficient at an estimated rate of 0.1094 and 0.3713 , respectively. It is worthy of remark that the observed effects of Deborah number and Magnetic number on local skin friction coefficient (Table 2 and Table 3) are in tandem with that of Ramesh et al. [13]. Table 4 show the impact of Brownian motion parameter $(\mathrm{Nb})$ on local Nusselt and Sherwood numbers. It is evident that the $\mathrm{Nb}$ increases in local Nusselt at the rate of 0.6703 and reduces the Sherwood numbers at the rate of -0.4517. It is important to remark that the outcome of Table 4 is in tandem with that of Khan and pop [34]. Table 5 indicates that the thermophoresis parameter $(\mathrm{Nt})$ experienced an exponential growth in both local Nusselt and Sherwood numbers in the fluid flow near the wall at the rate of 0.4393 and 0.3276 , respectively. As a result of this, it is worthy of remark that the outcome of Table 5 is in tandem with Khan and pop [34] and Ramesh et al. [13]. Table 6 reveals the impact of Lewis number on local skin friction coefficient, Nusselt and Sherwood numbers in the fluid flow at the

Table 1. Results that Compare the present study with that of Ramesh et al. [13] when $\beta=\gamma=0, M=N r=0$ and $\operatorname{Pr}=10, L e=1.0, A=0.3, \delta=1.0$.

\begin{tabular}{cccccc}
\hline \multirow{2}{*}{$N t$} & $N b$ & \multicolumn{2}{c}{ Ramesh et al. [13] } & \multicolumn{2}{c}{ Present study } \\
\cline { 3 - 6 } & & $-\theta(0)$ & $-\phi(0)$ & $-\theta(0)$ & $-\phi(0)$ \\
\hline 0.1 & 0.1 & 0.9523 & 2.1293 & 0.9524 & 2.1294 \\
0.3 & 0.1 & 0.5200 & 2.5286 & 0.5201 & 2.5287 \\
0.5 & 0.1 & 0.3210 & 3.0350 & 0.3211 & 3.0351 \\
0.1 & 0.1 & 0.9523 & 2.1293 & 0.9524 & 2.1294 \\
0.1 & 0.3 & 0.2520 & 2.4100 & 0.2521 & 2.4101 \\
0.1 & 0.5 & 0.0541 & 2.3835 & 0.0542 & 2.3836 \\
\hline
\end{tabular}


Table 2. Variation in local skin friction $f^{\prime \prime}(0)$, Nusselt number $-\theta^{\prime}(0)$, and Sherwood number $-\phi^{\prime}(0)$ with Deborah number $(\beta)$ when $M=0.5, N r=2.0, L e=1.0$, $\operatorname{Pr}=3.0, \quad N t=0.1, \quad N b=0.1, \gamma=0.2, A=0.3, \delta=1.0$.

\begin{tabular}{cccc}
\hline$\beta$ & $f^{\prime \prime}(0)$ & $-\theta^{\prime}(0)$ & $-\phi^{\prime}(0)$ \\
\hline 0.0 & 1.2247 & 0.9310 & 0.8602 \\
0.2 & 1.2490 & 0.9261 & 0.8598 \\
0.5 & 1.2797 & 0.9237 & 0.8582 \\
$S_{l p}$ & 0.1094 & 0.01408 & 0.00411 \\
\hline
\end{tabular}

Table 3. Variation in local skin friction $f^{\prime \prime}(0)$, Nusselt number $-\theta^{\prime}(0)$, and Sherwood number $-\phi^{\prime}(0)$ with Magnetic parameter $(M)$ when $\beta=0.2, N r=2.0, L e=1.0$, $\operatorname{Pr}=3.0, \quad N t=0.1, \quad N b=0.1, \quad \gamma=0.2, \quad A=0.3, \delta=1.0$.

\begin{tabular}{cccc}
\hline$M$ & $f^{\prime \prime}(0)$ & $-\theta^{\prime}(0)$ & $-\phi^{\prime}(0)$ \\
\hline 0.1 & 1.0617 & 0.9934 & 0.8525 \\
0.5 & 1.2490 & 0.9261 & 0.8598 \\
2.0 & 1.7797 & 0.7635 & 0.8769 \\
$S_{l p}$ & 0.3713 & 0.1176 & -0.0125 \\
\hline
\end{tabular}

Table 4. Variation in local skin friction $f^{\prime \prime}(0)$, Nusselt number $-\theta^{\prime}(0)$, and Sherwood number $-\phi^{\prime}(0)$ with Brownian motion parameter $(N b)$ when $\beta=0.2, M=0.5$, $N r=2.0, L e=1.0, \quad \operatorname{Pr}=3.0, N t=0.1, \gamma=0.2, A=0.3, \delta=1.0$.

\begin{tabular}{cccc}
\hline$N b$ & $f^{\prime \prime}(0)$ & $-\theta^{\prime}(0)$ & $-\phi^{\prime}(0)$ \\
\hline 0.1 & 1.2490 & 0.9261 & 0.8598 \\
0.3 & 1.2490 & 0.7354 & 1.2458 \\
1.0 & 1.2490 & 0.3051 & 1.3587 \\
$S_{l p}$ & 0 & 0.6703 & -0.4517 \\
\hline
\end{tabular}

Table 5. Variation in local skin friction $f^{\prime \prime}(0)$, Nusselt number $-\theta^{\prime}(0)$, and Sherwood number $-\phi^{\prime}(0)$ with thermophoresis parameter $(N t)$ when $\beta=0.2, \quad M=0.5$, $N r=2.0, L e=1.0, \operatorname{Pr}=3.0, N b=0.1, \gamma=0.2, A=0.3, \delta=1.0$.

\begin{tabular}{cccc}
\hline$N t$ & $f^{\prime \prime}(0)$ & $-\theta^{\prime}(0)$ & $-\phi^{\prime}(0)$ \\
\hline 0.1 & 1.2490 & 0.9261 & 0.8598 \\
0.3 & 1.2490 & 0.8108 & 0.7386 \\
1.0 & 1.2490 & 0.5222 & 0.5476 \\
$S_{l p}$ & 0 & 0.4393 & 0.3276 \\
\hline
\end{tabular}

wall. It is evident that the Le experienced significant reduction in local Sherwood number at the rate of -0.6468 , which is in tandem with the result of Ramesh et al. [8] and Suneetha et al. [27]. The results presented as Table 7 show that local 
Nusselt and Sherwood numbers are decreasing functions of Prandtl number Pr with the $S_{l p}$ been -0.1262 and -0.1656 , respectively. It is worthy of remark that results presented in Table 7 is in tandem with that of Baoku [10] and Kandasamy et al. [35]. Table 8 unravels the influence of radiation parameter $(\mathrm{Nr})$ on local skin friction, Nusselt and Sherwood numbers. It is evident that the local Nusselt and Sherwood numbers are increasing function of $\mathrm{Nr}$ with respect to the $S_{l p}$ been 0.0127 and 0.00525 , accordingly. It is worthy of remark that the observed effect of radiation parameter on the local Nusselt number contradicts that of Gireesha et al. [36]. Table 9 reveals the impact of chemical reaction parameter on local skin friction coefficient, Nusselt, and Sherwood numbers. It is evident that the local skin friction coefficient has no effect on the chemical reaction parameter. However, the local Sherwood number regressed the fluid flow at the

Table 6. Variation in local skin friction $f^{\prime \prime}(0)$, Nusselt number $-\theta^{\prime}(0)$, and Sherwood number $-\phi^{\prime}(0)$ with Lewis number (Le) when $\beta=0.2, M=0.5, \quad N r=2.0$, $\operatorname{Pr}=3.0, N t=0.1, N b=0.1, \gamma=0.2, A=0.3, \delta=1.0$.

\begin{tabular}{cccc}
\hline$L e$ & $f^{\prime \prime}(0)$ & $-\theta^{\prime}(0)$ & $-\phi^{\prime}(0)$ \\
\hline 1.0 & 1.2490 & 0.9261 & 0.8598 \\
2.0 & 1.2490 & 0.9041 & 1.6033 \\
3.0 & 1.2490 & 0.8938 & 2.1534 \\
$S_{l p}$ & 0 & 0.0162 & -0.6468 \\
\hline
\end{tabular}

Table 7. Variation in local skin friction $f^{\prime \prime}(0)$, Nusselt number $-\theta^{\prime}(0)$, and Sherwood number $-\phi^{\prime}(0)$ with Prandtl number $(P r)$ when $\beta=0.2, M=0.5, N r=2.0$, $L e=1.0, N t=0.1, N b=0.1, \gamma=0.2, A=0.3, \delta=1.0$.

\begin{tabular}{cccc}
\hline$P r$ & $f^{\prime \prime}(0)$ & $-\theta^{\prime}(0)$ & $-\phi^{\prime}(0)$ \\
\hline 2.0 & 1.2490 & 0.7176 & 0.6835 \\
3.0 & 1.2490 & 0.9261 & 0.8598 \\
7.0 & 1.2490 & 1.3762 & 1.5151 \\
$S_{\text {lp }}$ & 0 & -0.1262 & -0.1656 \\
\hline
\end{tabular}

Table 8. Variation in local skin friction $f^{\prime \prime}(0)$, Nusselt number $-\theta^{\prime}(0)$, and Sherwood number $-\phi^{\prime}(0)$ with Radiation parameter $(N r)$ when $\beta=0.2, M=0.5, L e=1.0$, $\operatorname{Pr}=3.0, N t=0.1, N b=0.1, \gamma=0.2, A=0.3, \delta=1.0$.

\begin{tabular}{cccc}
\hline$N r$ & $f^{\prime \prime}(0)$ & $-\theta^{\prime}(0)$ & $-\phi^{\prime}(0)$ \\
\hline 0.0 & 1.2490 & 0.8477 & 0.9998 \\
2.0 & 1.2490 & 0.9261 & 0.8598 \\
7.0 & 1.2490 & 0.7845 & 0.9307 \\
$S_{l p}$ & 0 & 0.0127 & 0.00525 \\
\hline
\end{tabular}


Table 9. Variation in local skin friction $f^{\prime \prime}(0)$, Nusselt number $-\theta^{\prime}(0)$, and Sherwood number $-\phi^{\prime}(0)$ with Chemical reaction parameter $(\gamma)$ when $\beta=0.2, M=0.5$, $N r=2.0, L e=1.0, \quad \operatorname{Pr}=3.0, N t=0.1, N b=0.1, A=0.3, \delta=1.0$.

\begin{tabular}{cccc}
\hline$\gamma$ & $f^{\prime \prime}(0)$ & $-\theta^{\prime}(0)$ & $-\phi^{\prime}(0)$ \\
\hline 0.0 & 1.2490 & 0.9373 & 0.5001 \\
0.2 & 1.2490 & 0.9261 & 0.8598 \\
0.5 & 1.2490 & 0.9161 & 1.2558 \\
$S_{l p}$ & 0 & 0.0417 & -1.4963 \\
\hline
\end{tabular}

Table 10. Variation in local skin friction $f^{\prime \prime}(0)$, Nusselt number $-\theta^{\prime}(0)$, and Sherwood number $-\phi^{\prime}(0)$ with Navier slip parameter $(\delta)$ when $\beta=0.2, M=0.5$, $N r=2.0, L e=1.0, \quad P r=3.0, N t=0.1, N b=0.1, \gamma=0.2, A=0.3$.

\begin{tabular}{cccc}
\hline$\delta$ & $f^{\prime \prime}(0)$ & $-\theta^{\prime}(0)$ & $-\phi^{\prime}(0)$ \\
\hline 1.0 & 0.5027 & 0.5908 & 0.8260 \\
2.0 & 0.3252 & 0.4709 & 0.8170 \\
3.0 & 0.2422 & 0.4033 & 0.8121 \\
$S_{l p}$ & -0.1303 & 0.0938 & 0.00695 \\
\hline
\end{tabular}

wall at an estimated rate of -1.4963 , which is in good agreement with the result of Ibrahim and Negera [11] and Ramesh et al. [13]. Table 10 show that the Navier slip parameter $(\delta)$ is a suitable factor to increase local Nusselt and Sherwood numbers. However, Table 10 indicates that both the local nusselt andlocal Sherwood number are increasing function of $\delta$ with respect to the $S_{t p}$ been 0.0938 and 0.00695 , respectively. Also, it shows that the local skin friction coefficient reduces at the rate of -0.1303 . It is important to remark that the results illustrated in Table 10 do not corroborate with that of Rashidi et al. [20] and Seth et al. [37].

Figure 2(a) describes the Deborah number $\beta$ impact on the velocity plot. It can be observed that the velocity Profile and boundary layer thickness retards with an increase in Deborah number $\beta$. Deborah number $\beta$ depicts the ratio of the relaxation time $k_{0}$ of the upper convected Maxwell fluid to observation time; see Table 2. Figure 2(b) shows the impact of Magnetic parameter $(M)$ on the velocity distribution. This distribution retards owing to the magnetic field inducement of a drag force called Lorentz force that opposes and slows down the motion of the fluid in the boundary layer.

The Brownian motion parameter $(N b)$ influence on temperature and concentration plots are given in Figure 2(c) and Figure 2(d). The temperature plot $\theta(\eta)$ increases with $N b$ within the region $0 \leq \eta \leq 4$ and the elevation is estimated as 0.1500 at the wall. Although, temperature plot $\theta(\eta)$ increases slightly at an estimated rate of 0.0087 till the free stream. The rise in temperature is due to the effect of the heat capacity of the nanoparticles, while the concentration 

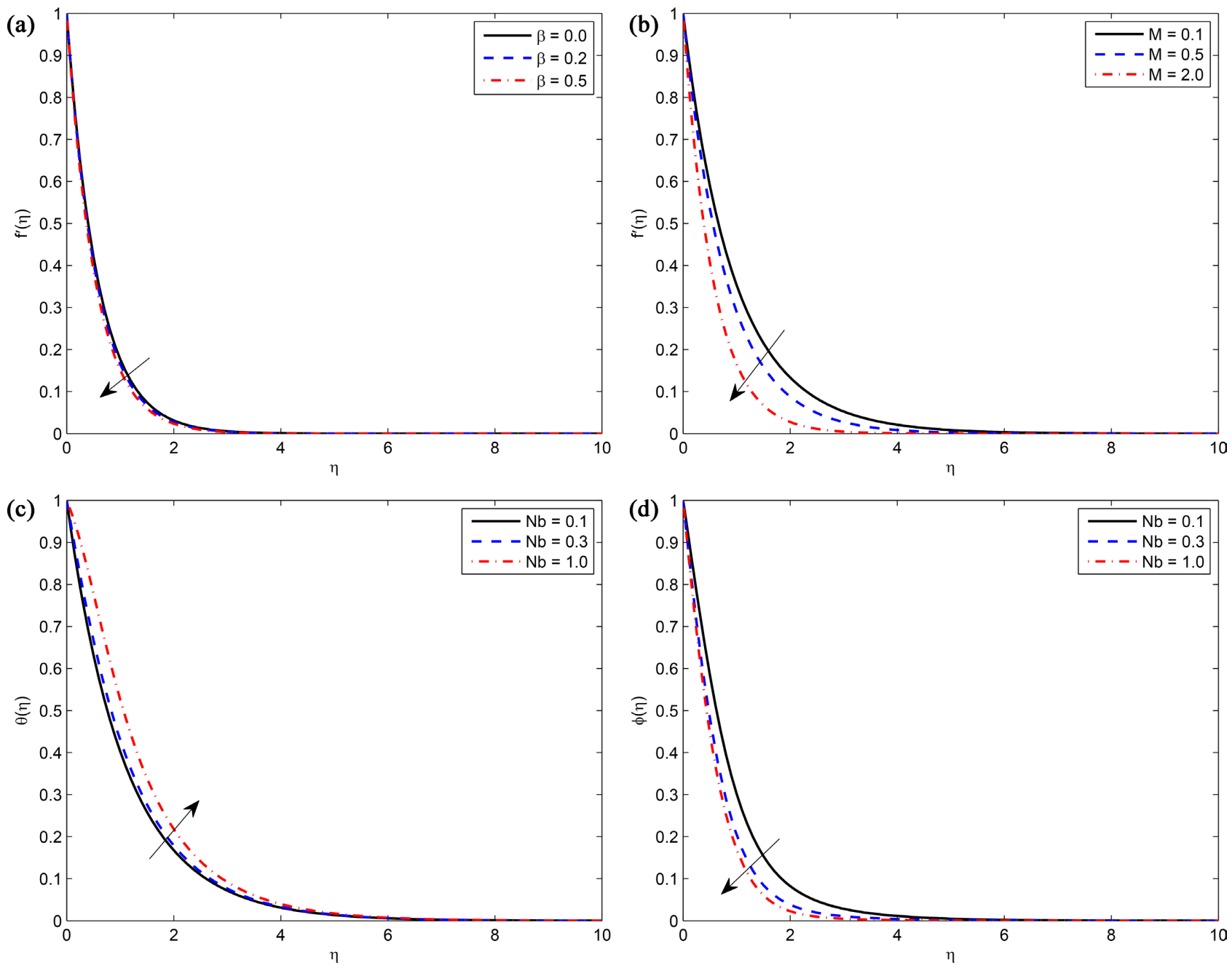

Figure 2. Variations of different parameters on velocity, temperature, and concentration distributions. (a) $f^{\prime}(\eta)$ vs $\eta$ for different $\beta$; (b) $f^{\prime}(\eta)$ vs $\eta$ for different $M$; (c) $\theta(\eta)$ vs $\eta$ for various $N b$; (d) $\phi(\eta)$ vs $\eta$ for various $N b$.

retards as the Brownian motion parameter $(N b)$ increases within the region $0 \leq \eta \leq 4$ at an estimated rate of 0.08670 and slightly retards at an estimated rate of -0.01610 till free stream.

Figure 3(a) and Figure 3(b), show that temperature and concentration gradients are elevating functions of thermophoresis parameter $(N t)$. The temperature gradient $\theta(\eta)$ grows with $N t$ within the region $0 \leq \eta \leq 6$ at an estimated rate of 0.0932 and at $\eta>6$, it increases slightly at an estimated rate of 0.0093 . The rise in temperature is owing to the fact that the nanoparticles move from a hot to cold region as a result of acquiring higher kinetic energy under the influence of temperature gradient. Also, the concentration gradient $\phi(\eta)$ increases with $N t$ within the region $0 \leq \eta \leq 5.7$ at an estimated rate of 0.3585 and at $\eta>5.7$, it proliferates slightly at an estimated rate of 0.0162 . The rise in concentration is a result of larger species exhibiting positive thermophoretic behaviour. Figure $3(c)$ exhibits the effect of Lewis number $(L e)$ on the concentration plot. Obviously, the fluid concentration diminishes as Le proliferates, this happens as 

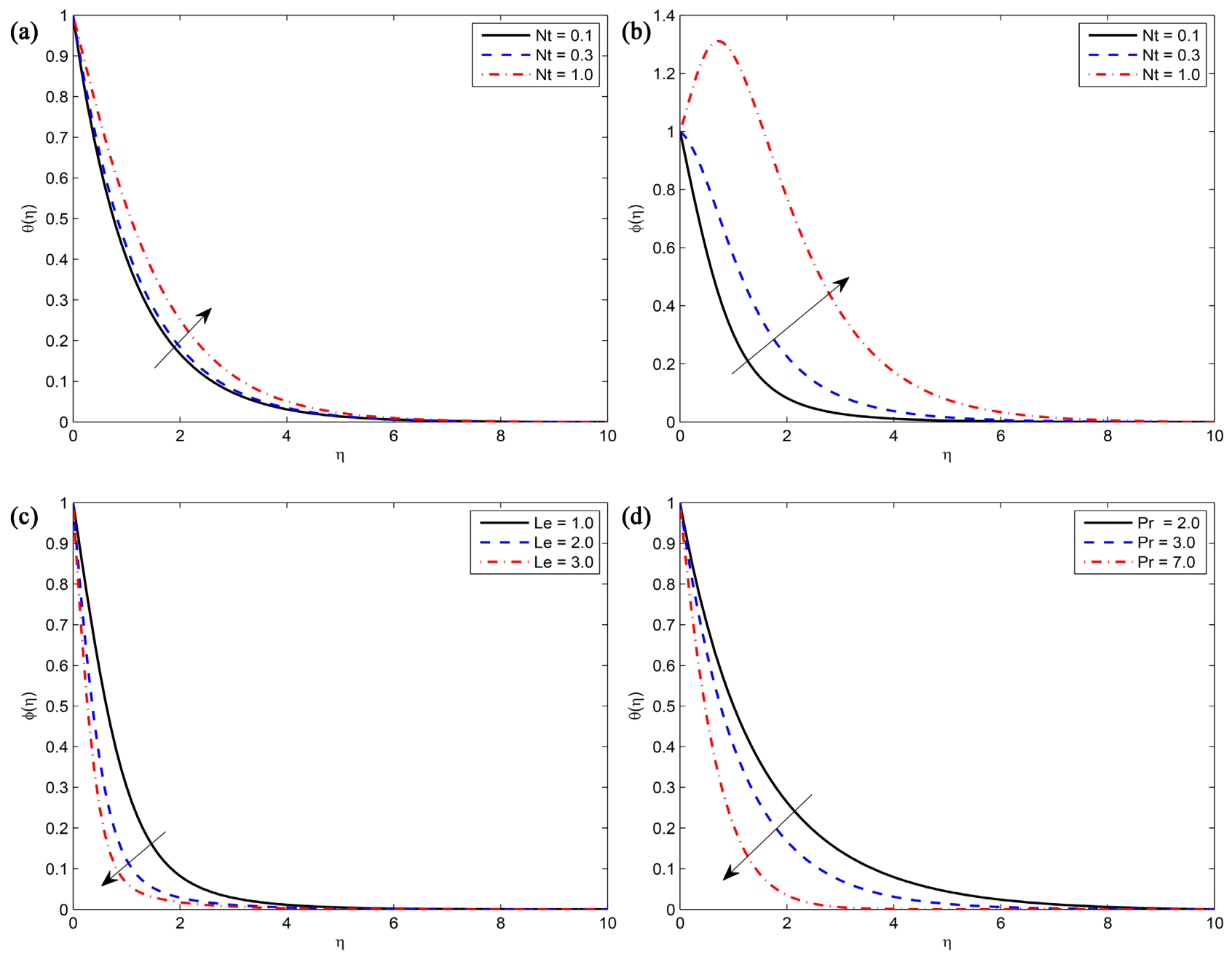

Figure 3. Variations of different parameters on temperature, and concentration plots. (a) $\theta(\eta)$ vs $\eta$ for different $N t$; (b) $\phi(\eta)$ vs $\eta$ for different $N t$, (c) $\phi(\eta)$ vs $\eta$ for different $L e$; (d) $\theta(\eta)$ vs $\eta$ for various Pr.

a result of the rate of mass transfer in the fluid.

Figure 3(d) and Figure 4(a), depicts the Prandtl number $(P r)$ action on the temperature and concentration curves. Fluids with higher $\operatorname{Pr}$ have relatively low thermal conductivity, which retards conduction and thereby the thermal boundary layer thickness, as a result, temperature and concentration plots decrease. The graphical plot of temperature and concentration distribution for Radiation parameter $(N r)$ is displayed in Figure 4(b) and Figure 4(c). It is observed that the temperature plot of the fluid is influenced considerably and rises as the $(N r)$ escalates. This is due to the influence of thermal radiation on heat transfer rate of the fluid because it involves the conversion of thermal energy into energy in the form of electromagnetic radiation. Also, the concentration distribution retards within the region $0 \leq \eta \leq 2$ and then increases at $\eta>2$ as Radiation parameter $(N r)$ rises. Figure $4(\mathrm{~d})$ describes the Chemical reaction parameter $\gamma$ impact on concentration plot. The Chemical reaction parameter $(\gamma)$ retards the concentration of species during suction, thereby leading to deterioration in the 

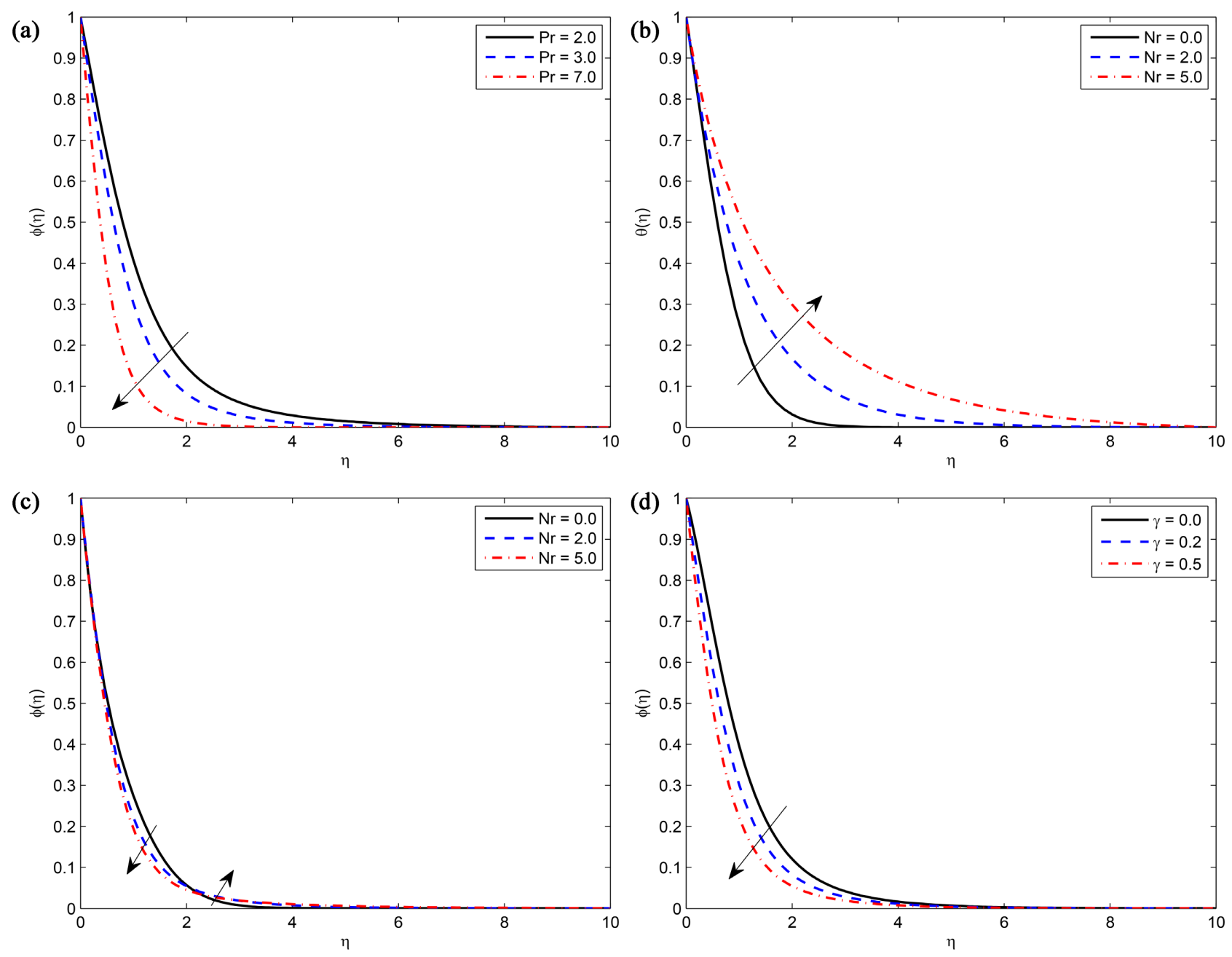

Figure 4. Variations of different parameters on temperature, and concentration plots. (a) $\phi(\eta)$ vs $\eta$ for various $\operatorname{Pr}$, (b) $\theta(\eta)$ vs $\eta$ for various $N r$, (c) $\phi(\eta)$ vs $\eta$ for various $N r$, (d) $\phi(\eta)$ vs $\eta$ for different $\gamma$.

concentration plot.

Navier slip parameter $(\delta)$ impact on velocity, temperature, and concentration distributions was presented in Figure 5(a) to Figure 5(c). Figure 5(a) indicates that the velocity distribution is an increasing function of Navier slip parameter $(\delta)$. It is evident from the graph that $\delta$ influences the flow of fluid beyond the moving plate and the amount of slip $1-f^{\prime}(0)$ drastically decrease with $\delta$ from partial slip situation $\delta=1$ and towards full slip $\delta \rightarrow \infty$, whereas Figure 5(b) and Figure 5(c) show that temperature and concentration distributions rises as the Navier slip parameter $(\delta)$ intensifies.

\section{Conclusions}

The effects of various governing parameters on fluid flow, heat and mass transfer characteristics on chemically reactive hydromagnetic Maxwell fluid conveying tiny particles due to Navier partial slip had been investigated. The numerical results are presented in tables and plots. The following conclusions were deduced 

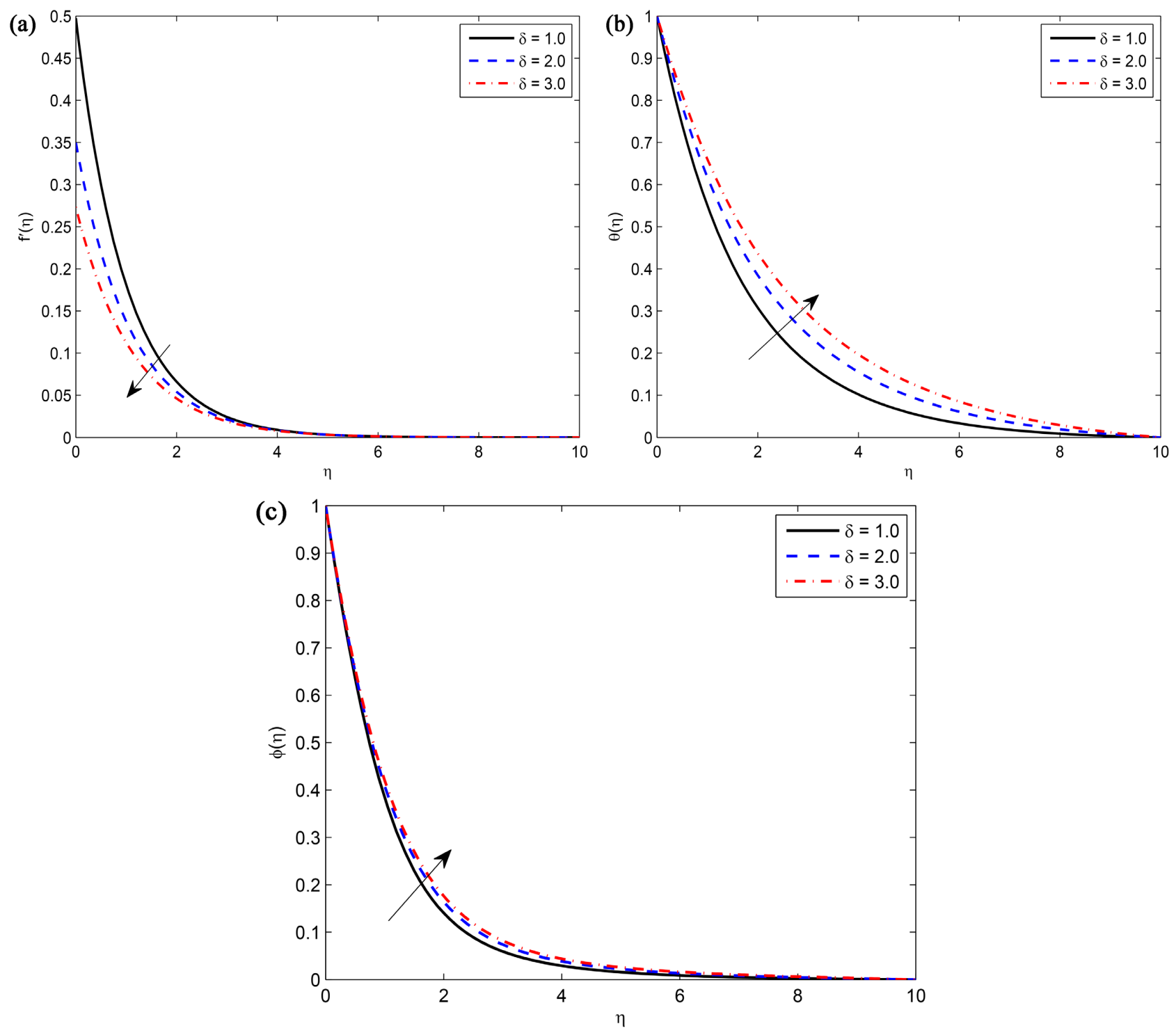

Figure 5. Navier partial slip parameter impact on velocity, temperature, and concentration plots. (a) $f^{\prime}(\eta)$ vs $\eta$ for different $\delta$; (b) $\theta(\eta)$ vs $\eta$ for different $\delta$; (c) $\phi(\eta)$ vs $\eta$ for different $\delta$.

from our findings:

- The intensity in the Deborah number $(\beta)$ leads to a slight reduction in the velocity graph. Moreover, the effect of Hartmann number $(M)$ leads to an obvious decline in the velocity profile.

- The rise in Brownian motion parameter $(N b)$ proliferates the temperature gradient.

- Thermal boundary layer thickness rises and heat transfer rate retards when the thermophoretic effect intensifies.

- Thermal radiation influenced the heat transfer rate in the thermal boundary layer thickness. Furthermore, the temperature distribution is influenced considerably and rises as the Radiation parameter $(\mathrm{Nr})$ escalates.

- Navier partial slip parameter $(\delta)$ escalates as the velocity field deteriorates at 
the boundary layer thickness. Meanwhile, the temperature and concentration fields rise as the Navier partial slip parameter $(\delta)$ proliferates.

- The concentration boundary layer thickness retards with an increase in Thermophoresis parameter $(N t)$, but intensifies with a decrease in Brownian motion parameter $(N b)$, Lewis number $(L e)$, Prandtl number $(P r)$, and Chemical reaction parameter $(\gamma)$. Also, the concentration distribution retards within the region $0 \leq \eta \leq 2$ and then increases at $\eta>2$ as the Radiation parameter $(\mathrm{Nr})$ rises.

\section{Conflicts of Interest}

The authors declare no conflicts of interest.

\section{References}

[1] Roylance, D. (2001) Engineering Viscoelasticity. Massachusetts Institute of Technology, Cambridge, 8-11.

[2] Aliakbar, V., Alizadeh, P.A. and Sadeghy, K. (2009) The Influence of Thermal Radiation on MHD Flow of Maxwellian Fluids above Stretching Sheets. Communications in Nonlinear Science and Numerical Simulation, 14, 779-794. https://doi.org/10.1016/j.cnsns.2007.12.003

[3] Motsa, S.S., Hayat, T. and Aldossary, O.M. (2012) MHD Flow of Upper-Convected Maxwell Fluid over Porous Stretching Sheet Using Successive Taylor Series Linearization Method. Applied Mathematics and Mechanics, 33, 975-990. https://doi.org/10.1007/s10483-012-1599-x

[4] Noor, F. and Mohammad, N. (2012) Analysis for MHD Flow of a Maxwell Fluid Past a Vertical Stretching Sheet in the Presence of Thermophoresis and Chemical Reaction. International Journal of Physical and Mathematical Sciences, 6, 485-489.

[5] Sajid, M., Abbas, Z., Ali, N., Javed, T. and Ahmad, I. (2013) Slip Flow of a Maxwell Fluid Past a Stretching Sheet. Walailak Journal of Science and Technology, 11, 1093-1103.

[6] Shateyi, S. and Marewo, G.T. (2013) A New Numerical Approach of MHD Flow with Heat and Mass Transfer for the UCM fluid over a Stretching Surface in the Presence of Thermal Radiation. Mathematical Problems in Engineering, 2013, 1-8. https://doi.org/10.1155/2013/670205

[7] Adegbie, K.S., Omowaye, A.J., Disu, A.B. and Animasaun, I.L. (2015) Heat and Mass Transfer of Upper Convected Maxwell Fluid Flow with Variable Thermo-Physical Properties over a Horizontal Melting Surface. Applied Mathematics, 6, 1362-1379. https://doi.org/10.1155/2013/670205

[8] Ramesh, G.K., Gireesha, B.J., Hayat, T. and Alsaedi, A. (2016) Stagnation Point Flow of Maxwell Fluid towards a Permeable Surface in the Presence of Nanoparticles. Alexandria Engineering Journal, 55, 857-865.

https://doi.org/10.1016/j.aej.2016.02.007

[9] Baoku, I.G. and Falade, K.I. (2019) MHD Maxwell Reactive Flow with Velocity Slip over a Stretching Surface with Prescribed Heat Flux in the Presence of Thermal Radiation in a Porous Medium. Journal of Advances in Mathematics and Computer Science, 31, 1-25. https://doi.org/10.9734/jamcs/2019/v31i330116

[10] Baoku, I.G. (2018) Influence of Chemical Reaction, Viscous Dissipation and Joule Heating on MHD Maxwell Fluid Flow with Velocity and Thermal Slip over a Stretching Sheet. Journal of Advances in Mathematics and Computer Science, 28, 1-20. 
https://doi.org/10.9734/JAMCS/2018/42481

[11] Ibrahim, W. and Negera, M. (2020) MHD Slip Flow of Upper-Convected Maxwell Nanofluid over a Stretching Sheet with Chemical Reaction. Journal of the Egyptian Mathematical Society, 28, Article No. 7. https://doi.org/10.1186/s42787-019-0057-2

[12] Imran, M.A., Riaz, M.B., Shah, N.A. and A.A. (2018) Boundary Layer Flow of MHD Generalized Maxwell Fluid over an Exponentially Accelerated Infinite Vertical Surface with Slip and Newtonian Heating at the Boundary. Results in Physics, 8, 1061-1067. https://doi.org/10.1016/j.rinp.2018.01.036

[13] Ramesh, G.K., Gireesha, B. J., Hayat, T. and Alsaedi, A. (2015) MHD Flow of Maxwell Fluid Over a Stretching Sheet in the Presence of Nanoparticles, Thermal Radiation and Chemical Reaction: A Numerical Study. Journal of Nanofluids, 4, 100-106. https://doi.org/10.1166/jon.2015.1133

[14] Ramesh, G.K., Roopa, G.S., Gireesha, B.J., Shehzad, S.A. and Abbasi, F.M. (2017) An Electro-Magneto-Hydrodynamic Flow Maxwell Nanoliquid Past a Riga Plate: A Numerical Study. Journal of the Brazilian Society of Mechanical Sciences and Engineering, 39, 4547-4554. https://doi.org/10.1007/s40430-017-0900-Z

[15] Omowaye, A.J. and Animasaun, I.L. (2016) Upper-Convected Maxwell Fluid Flow with Variable Thermo-Physical Properties over a Melting Surface Situated in Hot Environment Subject to Thermal Stratification. Journal of Applied Fluid Mechanics, 9, 1777-1790.

[16] Koriko, O.K., Adegbie, K.S., Omowaye, A.J. and Animasaun, I.L. (2016) Boundary layer Analysis of Upper Convected Maxwell Fluid Flow with Variable Thermo-Physical Properties over a Melting Thermally Stratified Surface. FUTA Journal of Research in Sciences, 12, 287-298.

[17] Shehzad, S.A., Alsaedi, A. and Hayat, T. (2013) Hydromagnetic Steady Flow of Maxwell Fluid over a Bidirectional Stretching Surface with Prescribed Surface Temperature and Prescribed Surface Heat Flux. PLoS ONE, 8, Article ID: e68139. https://doi.org/10.1371/journal.pone.0068139

[18] Salah, F., Abdul Aziz, Z., Ayem, M. and Ling Chuan Ching, D. (2013) MHD Accelerated Flow of Maxwell Fluid in a Porous Medium and Rotating Frame. International Scholarly Research Notices, 13, Article ID: 485805.

https://doi.org/10.1155/2013/485805

[19] Choi, S.U.S. and Eastman, J.A. (1995) Enhancing Thermal Conductivity of Fluids with Nanoparticles. Proceedings of the ASME International Mechanical Engineering Congress and Exposition, Vol. 66, San Francisco, 12-17 November 1995, 99-105.

[20] Rashidi, M.M., Ganesh, N.V., Abdulhakeem, A.K. and Ganga, B. (2014) Buoyancy Effect on MHD Flow of Nanofluid over a Stretching Sheet in the Presence of Thermal Radiation. Journal of Molecular Liquids, 198, 234-238.

https://doi.org/10.1016/j.molliq.2014.06.037

[21] Rout, B.C. and Mishra, S.R. (2018) Thermal Energy Transport on MHD Nanofluid flow over a Stretching Surface: A Comparative Study. Engineering Science and Technology, An International Journal, 21, 60-69.

https://doi.org/10.1016/j.jestch.2018.02.007

[22] Ho, V.B. (2018) Fluid State of Dirac Quantum Particles. Journal of Modern Physics, 9, 2402-2419. https://doi.org/10.4236/jmp.2018.914154

[23] Shoaib, M., Raja, M.A., Sabir, M.T., Islam, S., Shah, Z., Kumam, P. and Alrabaiah, H. (2020) Numerical Investigation for Rotating Flow of MHD Hybrid Nanofluid with Thermal Radiation over a Stretching Sheet. Scientific Reports, 10, Article No. 18533. https://doi.org/10.1038/s41598-020-75254-8 
[24] Zainal, N.A., Nazar, R., Naganthran, K. and Pop, I. (2020) MHD Flow and Heat Transfer of Hybrid Nanofluid over a Permeable Moving Surface in the Presence of Thermal Radiation. International Journal of Numerical Methods for Heat and Fluid Flow, 31, 858-879. https://doi.org/10.1108/HFF-03-2020-0126

[25] Animasaun, I.L., Mahanthesh, B. and Koriko, O.K. (2018) On the Motion of non-Newtonian Eyring-Powell Fluid Conveying Tiny Gold Particles Due to Generalized Surface Slip Velocity and Buoyancy. International Journal of Applied and Computational Mathematics, 4, Article No. 137.

https://doi.org/10.1007/s40819-018-0571-1

[26] Navier, C.L.M.H. (1823) Memoire sur les lois du Mouvement des Fluides. Memoires de 1 Academie Royale des Sciences de P institut de France, 6, 389-440.

[27] Suneetha, S., Subbarayudu, K., Wahidunnisa, L. and Reddy, P.B.A. (2020) Navier Slip Condition on Time-Dependent Radiating Nanofluid with the Soret Effect. Engineering Transactions, 68, 177-198.

[28] Ren, W., Trinh, P.H. and Weinan, E. (2015) On the Distinguished Limits of the Navier Slip Model of the Moving Contact Line Problem. Journal of Fluid Mechanics, 772, 107-126. https://doi.org/10.1017/jfm.2015.173

[29] Fernandes, C., Ferras, L.L., Habla, F., Carneiro, O.S. and Nobrega, J.M. (2019) Implementation of Partial Slip Boundary Conditions in an Open-Source Finite-Volume-Based Computational Library. Journal of Polymer Engineering, 39, 377-387. https://doi.org/10.1515/polyeng-2018-0343

[30] Venkatesan, J. and Ganesan, S. (2015) On the Navier-Slip Boundary Condition for Computations of Impinging Droplets. 2015 IEEE 22nd International Conference on High Performance Computing Workshops, Bengaluru, 16-19 December 2015, 2-11. https://doi.org/10.1109/HiPCW.2015.10

[31] Fang, M., Gilbert, R.P. and Liu, X. (2010) A Squeeze Flow Problem with a Navier Slip Condition. Mathematical and Computer Modelling, 52, 268-277. https://doi.org/10.1016/j.mcm.2010.02.024

[32] Bolanos, S.J. and Vernescu, B. (2017) Derivation of the Navier Slip and Slip Length for Viscous Flows over a Rough Boundary. Physics of Fluids, 29, Article ID: 057103. https://doi.org/10.1063/1.4982899

[33] Buongirno, J. (2006) Convective Transport in Nanofluids. Journal of Heat Transfer, 128, 240-250. https://doi.org/10.1115/1.2150834

[34] Khan, W.A. and Pop, I. (2010) Boundary Layer Flow of a Nanofluid Past a Stretching Sheet. International Journal of Heat and Mass Transfer, 53, 2477-2483. https://doi.org/10.1016/j.ijheatmasstransfer.2010.01.032

[35] Kandasamy, R., Muhaimin, I. and Mohamad, R. (2013) Thermophoresis and Brownian Effects on MHD Boundary Layer Flow of a Nanofluid in the Presence of Thermal Stratification Due to Solar Radiation. International Journal of Mechanical Sciences, 70, 146-154. https://doi.org/10.1016/j.ijmecsci.2013.03.007

[36] Gireesha, B.J., Mahanthesh, B., Gorla, R.S.R. and Krupalakshmi, K.L. (2015) Mixed Convection Two-Phase Flow of Maxwell Fluid under the Influence of Non-Linear Thermal Radiation, Non-Uniform Heat Source/Sink and Fluid-Particle Suspension. Ain Shams Engineering Journal, 9, 735-746. https://doi.org/10.1016/j.asej.2016.04.020

[37] Seth, G.S., Bhattacharyya, A. and Mishra, M.K. (2019) Study of Partial Slip Mechanism on Free Convection Flow of Viscoelastic Fluid Past a Nonlinearly Stretching Surface. Computational Thermal Sciences, 11, 1-13. https://doi.org/10.1615/ComputThermalScien.2018024728 


\section{Nomenclature}

$u \quad$ Velocity component along $\mathrm{x}$ coordinate $\left[\mathrm{ms}^{-1}\right]$

$V \quad$ Velocity component along y coordinate $\left[\mathrm{ms}^{-1}\right]$

$x, y \quad$ Cartesian coordinates [-]

$T_{\infty} \quad$ Temperature of the fluid far away from the wall [K]

$T \quad$ Temperature of the fluid [K]

$T_{w} \quad$ Plate temperature [K]

$k_{0} \quad$ Upper Convected Maxwell fluid relaxation time [s]

$f \quad$ Dimensionless velocity [-]

$B_{0} \quad$ Magnetic flux density $\left[\mathrm{kgs}^{-2} \cdot \mathrm{A}^{-1}\right]$

$D_{B} \quad$ Brownian diffusion coefficient $\left[\mathrm{m}^{2} \cdot \mathrm{s}^{-1}\right]$

$D_{T} \quad$ Thermophoresis diffusion coefficient $\left[\mathrm{m}^{2} \cdot \mathrm{s}^{-1}\right]$

$N \quad$ Navier Slip coefficient [m]

$k^{*} \quad$ Absorption coefficient [-]

$R \quad$ Chemical reaction rate $\left[\mathrm{mol} \cdot \mathrm{m}^{-1} \cdot \mathrm{s}^{-1}\right]$

$k \quad$ Thermal conductivity $\left[\mathrm{kg} \cdot \mathrm{ms}^{-3} \cdot \mathrm{K}^{-1}\right]$

$C \quad$ Nanoparticle volume fraction $[\mathrm{K}]$

$\Delta C \quad$ Nanoparticle volume fraction change rate $[\mathrm{K}]$

$C_{\infty} \quad$ Concentration of the fluid far away from the wall [K]

$S_{l p} \quad$ Slope of linear regression $[-]$

$C_{w} \quad$ Plate concentration $[\mathrm{K}]$

$c_{p} \quad$ Specific heat due to constant pressure $\left[\mathrm{J} \cdot \mathrm{kg}^{-1} \mathrm{~K}\right]$

\section{Greek Symbols}

$\alpha \quad$ Thermal diffusivity $\left[\mathrm{kg} \cdot \mathrm{ms}^{-3} \cdot \mathrm{K}^{-1}\right]$

$v \quad$ Kinematic viscosity $\left[\mathrm{m}^{2} \cdot \mathrm{s}^{-1}\right]$

$\rho \quad$ Density of the fluid $\left[\mathrm{kg} \cdot \mathrm{m}^{-3}\right]$

$\sigma^{*} \quad$ Stefan-Boltzman constant $\left[\mathrm{kg} \cdot \mathrm{s}^{-3} \cdot \mathrm{K}^{-1}\right]$

$\sigma \quad$ Electrical conductivity $\left[\Omega^{-1} \cdot \mathrm{m}^{-1}\right]$

$\tau \quad$ Ratio of the heat capacity of the nanoparticle material to the heat capacity of the base fluid [-]

$\eta \quad$ Similarity variable $[-]$

$\theta \quad$ Dimensionless temperature [-]

$\theta_{w} \quad$ Temperature ratio parameter [-]

$\phi \quad$ Dimensionless concentration [-]

$\phi_{w} \quad$ Concentration ratio parameter [-]

$\psi \quad$ Stream function [-]

\section{Subscripts}

f Base fluid

p Base particle 